\title{
Using Google translate in teaching and learning activities for English - medium - instruction (EMI) subjects
}

\author{
Phuong Anh, Nguyen; Thanh Loan T., Nguyen and Hong Nga T., Nguyen \\ Faculty of Auditing and Accounting \\ Hanoi University of Industry \\ Hanoi, Vietnam \\ anhnp_ktkt@haui.edu.vn
}

\begin{abstract}
In the age of globalization, translation has tended increasingly necessary in bilingual classrooms. The advancement of technology has provided useful tools for making translation easier and more convenient. The automatic tool "Google translate" is increasingly popular and used in many teaching-learning activities recently. The study provides a comprehensive and new insight into the strengths and weaknesses of Google translate. Through the comparison of machine translation and human translation on the aspects of task response, coherence, lexical resource, grammar and accuracy, it shows that there are some limitations in machine translation. which affects the quality of the translations. However, machine translation still plays an important role in supporting users, in terms of time and economic efficiency. Google Translation is a productive tool to assist individuals in learning and teaching in the field of specialized English-mediuminstruction subjects.
\end{abstract}

Keywords: Machine translation, Google Translate, Teaching and learning activities, Management Accounting module.

\section{INTRODUCTION}

In the era of globalization and multilingual communication along with the Fourth Industrial Revolution, translation activities play an important role in all aspects of life. It can be said that translation activities have existed since the beginning of human civilization, expressed at many different levels. Translationn is seen as a powerful tool with the mission of breaking down the wall of language differences, bridging the gap between countries through sharing cultural values. Advances in technology, especially in the field of information and communication, make the interaction between one country and other countries increasingly enhanced, so according to [13]: "Global communication cannot exist without translation". The explosion of international exchanges as well as the increasing demand for translation in many fields requires translators who can translate in a short time a large number of documents in various fields. The advancement of science has given birth to a solution to support humans, then machine translation is formed as an independent scientific trend. Machine translation is a part of the automatic translation system, although there are still some limitations, machine translation is currently considered the key of international social issues in the international information era [5].

Google Translate (GT) is one of the most popular machine translation tools in the world. Google translate is one of the applications developed by Google, a website that allows users to access information from all over the world at any time and from anywhere. Currently, Google translate can translate into more than 100 languages used in the world. In the era of globalization, students are required to read and understand many texts and documents that still use the original language from an international language, such as English. From there, students came up with the idea of translating these texts in instantaneous ways in a relatively short time. One of the effective tools is using Google translate.

In the trend of international integration, Hanoi University of Industry (HaUI) has been implementing a project to teach a number of specialized modules in English to improve English skills as a means to exchange and learn from the world. However, there are still some difficulties in teaching-learning activities due to language barriers. To support the teachinglearning process of lecturers and students, the research focuses on (i) assessing the strengths and weaknesses of the Google translate tool; (ii) determine the practical application of Google translate in teaching-learning activities in specialized subjects in English; thereby (iii) exploring the current situation of using GT as a supporting tool among HaUI students.

In this study, the examples are taken from the module of Management Accounting (ACCA) and its translation is processed by Google translation. The course belongs to the Department of Accounting Information Systems, Faculty of Accounting and Auditing and is taught in English, using the curriculum provided by ACCA.

\section{THEORETICAL PERSPECTIVES ON TRANSLATION}

\section{A. The term of translation}

Translation is a process of replacing meanings in one language into another by means of interpretations [13]. The translation process must consider the vocabulary, grammar and contextual situations in the source language, and then translate that text into the target language with the same meaning by considering the naturalness of the target language. Therefore, the equivalence of the source and target languages needs to be met to avoid misunderstanding by the receiver. According to [2], translation is a process or a product including literal translation, technical translation, subtitle or machine translation. The translation should have equivalence in meaning and context between the source and target languages. The result of the translation process must be readable so that the reader can easily understand the content of 
the translation. On the contrary, when the translated text is unreadable, it will be difficult and confusing for the reader.

\section{B. Machine translation}

Machine translation is a strand of natural language processing within the sub-discipline of artificial intelligence. Machine translation is a combination of language and computer science. Translations are "automatically translated from one language into one or more other languages, without human intervention in the translation process". At a basic level, machine translation performs an independent substitution of words in the source language into the target language, but it usually does not produce a good translation. Currently, machine translation is rapidly evolving to solve this problem by capturing statistics and neutral techniques, so that it can handle typographical differences, idiom translations, and unusual differences. Machine translation is a very valuable area of research, leading to the development of approaches in building high-quality translation software. Currently, custom domain names or professions are often available in translation software. This feature will narrow the range of allowed substitutions, resulting in improving the quality of translation results. Human intervention is also an alternative way to improve the quality of translation products. Some translation systems can improve the accuracy of the translation next time after the user can suggest corrections for the mistakes it has made.

\section{STRENGTHS AND WEAKNESSES OF GT}

\section{A. Introduction to Google Translate}

Machine translation developed by Google is called "Google Translate". It was first developed in 2007, using a system called SYSTRAN. Then, in 2010, Google moved to a new platform of machine translation according to the principle of "Statistical Machine Translation". Translation quality is increased over time as more and more texts are loaded with increasingly diverse structures and contexts. Since 2016, GT has used Neural Machine Translation (NMT) technology for most language pairs, which gives more accurate results than other methods. Recently, GT has supported more than 100 languages at different levels. Google translate can translate not only a word, but also a phrase, part of text, or a Web page. To translate a text, Google Translate searches different sets of documents to find the most appropriate translation pattern among human-translated texts.

\section{B. Strengths of $G T$}

Google translate has various advantages. First, it's free. It also offers multiple languages for input and output. The app also enables speech recognition, translates entire web pages, and uploads entire text files for quick translation.

[8] emphasized the advantages of Google translate in teaching English. Google translate allows users to access websites for free. Users just need to open the website in their browser or load the app in their widget to use the app. Photo recognition becomes a feature in the Google translate app on learners' smartphones to save time, especially when learners are trying to understand some English text. Students simply take a picture of the word or text, then let the tool do the job. In addition, this application also allows text input through the virtual keyboard, handwriting recognition or voice recognition.

\section{Weaknesses of $G T$}

Although Google translate offers many benefits, its role in teaching and learning activities as a mainstream aid is still controversial because of a number of limitations. One of the most mentioned limitations is that the translation from this application is not accurate for a sentence or a long text $[8,10]$. GT will provide a word-by-word translation in cases of translating a long sentence or paragraph. Google translate also can't process language as idioms or figurative. Therefore, the length of the text determines the quality of the translation, the shorter the text, the higher the quality. [12] tested google translate with six different types of documents, including: articles, minutes, notes, letters, quizzes and Powerpoint slides, only slides were for best results, because the slides do not contain full sentences but only phrases.

In addition, [3] also pointed out that google translate does not have a grammar function, so it cannot process grammatically correct sentences. Another limitation of this tool is that there is no context. This can cause misunderstandings in word choice. Word choice is the way of how learners choose words to express their ideas in their writing. Choosing the right words while writing ideas is one of the best ways to get the message across to the reader [11]. Word choice has a lot to do with vocabulary. Since vocabulary is defined as the words needed to convey students' ideas and meanings, vocabulary plays an important role in language. A well-organized article is one in which the reader can easily follow the writer's ideas, ideas need to be clearly organized, coherent and suitable word choice. Accordingly, google translate or machine translation cannot replace human.

\section{METHODOLOGY}

To answer research question, the paper is conducted based two methods as followed. First, data from the most popular machine translation tool, Google translate, will be collected to become a comparative document. The authors compared the translations between GT's and humans. In this method, Management Accounting materials provided by ACCA will be collected as examples for reference. The basic criteria for assessing the quality of a translation are responsiveness, coherence, vocabulary, grammar and accuracy.

Additionally, the paper aimed to investigate current situations of using GT among students who are currently studying Management Accounting delivered in English in Hanoi University of Industry. Thus, the paper distributed a survey questionnaire created by Google Forms to collect data on students' attitudes and feelings towards using GT for learning purposes. The five-point rating scale questionnaire was adapted from a questionnaire developed by [14]. Students were asked to complete the questionnaire in a given time to 
provide their purposes of using GT, attitudes on benefits, drawbacks as well as problems when using GT.

\section{FINDINGS AND DISCUSSION}

\section{A. The quality of Translations}

\section{Task response and Coherence}

With Google Translate, the response to translating a word, sentence, or entire web page is available with the click of a mouse or the touch of a finger.

Google translate relies on various available forms to translate from source language to target language. In some cases, language coherence may be lost. Individual words are processed at an increasing level by Google translate. Therefore, to increase the quality of the translation, the user should provide input in the form of basic templates to create context for the translated text.

The example below (Figure 1) is an illustration of a context-specific translation. If just translating the word "fixed" alone, it is not enough context for an accurate and appropriate translation, but when adding the word "cost" or the whole sentence, it is much clearer.

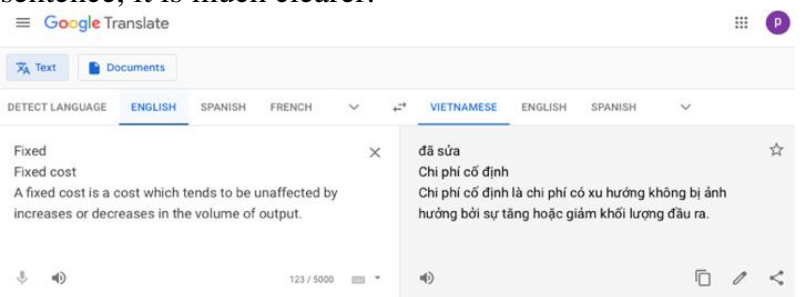

Fig. 1 Example of "Fixed cost"

Similarly, with the term "variable cost", if only one word "variable", google translate will result in a variable, but when placed in a specific context, adding the word "cost" or the whole sentence, the translation has already changed for more accurate results.

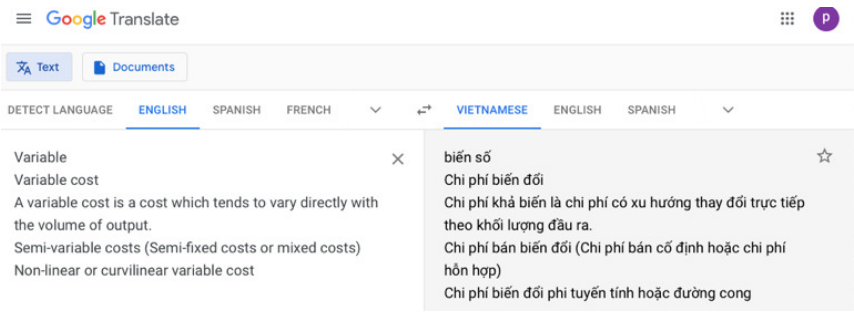

Fig. 2 Example of "Variable cost"

However, google translate is still limited, as mentioned above, the translations still result in translating from single words then combining them. If it needs more precise, the translation could have additional results such as: "fixed cost" or "variable cost". As another example, the terms "Non-linear variable cost" and "curvilinear variable cost" both mean the same translation as "non-linear variable cost" or "non-linear variable cost"

Vocabulary and Grammar
Regardless of the source language or the target language, for machine translation, the distinction between synonyms to use to suit a particular context is a challenge.

For example, the word "variance" can be translated as "variance" or "variance", but in management accounting, "cost variance" is understood as the difference in costs.

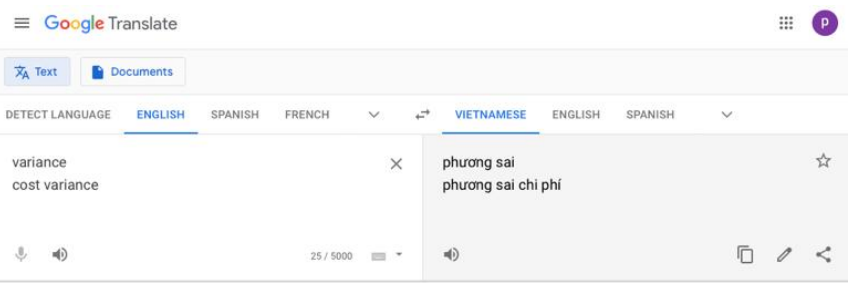

Fig. 3 Example of "cost variance"

In those cases, critical thinking in translation is needed when the vocabulary has multiple meanings or the existence of some special meanings in individual words. Therefore, students must apply critical thinking when searching and selecting equivalent words to choose the appropriate one.

An example of a plural word is the word "set". According to the Oxford dictionary, the word "set" has the largest number of meanings, in such cases, users need to think critically to choose words that match the context.

Accuracy

As mentioned previously, the semantic translation method focuses on accuracy, while the communicative translation method focuses on fluency. Hence, Google Translate can be useful on a word-by-word level, but actual accuracy is often lost in cases of grammar and accuracy. Two factors that can be used to assess the accuracy of a translation are the titles and terms in the translation.

Titles play an important role in translation because they are the first object that comes to learners. Most titles are translated literally and are closest to the source language.

The table below evaluates the titles and accuracy of translations from google translate.

TABLE I

Evaluation of the title and the accuracy of the translation from google translate

\begin{tabular}{|c|c|c|}
\hline Title & Translation from GT & Evaluation \\
\hline $\begin{array}{l}\text { Cost behaviour } \\
\text { patterns }\end{array}$ & $\begin{array}{l}\text { 'Các mẫu hành vi chi } \\
\text { phí' }\end{array}$ & $\begin{array}{l}\text { The meaning is not } \\
\text { clear } \\
\text { Dịch là "các cách } \\
\text { úng xử của chi phí" }\end{array}$ \\
\hline Fixed costs & 'Giá cố định’ & $\begin{array}{l}\text { Incorrect } \\
\text { Dịch đúng “chi phí } \\
\text { cố định" }\end{array}$ \\
\hline Step costs & 'Chi phí bước' & $\begin{array}{l}\text { Incorrect } \\
\text { Dịch đúng “chi phí } \\
\text { cấp bậc” }\end{array}$ \\
\hline Variable costs & 'Chi phí biến đổi' & Acceptable \\
\hline $\begin{array}{l}\text { Non-linear or } \\
\text { curvilinear variable } \\
\text { costs }\end{array}$ & $\begin{array}{l}\text { 'Chi phí biến đối phi } \\
\text { tuyến tính hoặc } \\
\text { đường cong' }\end{array}$ & Acceptable \\
\hline Semi-variable & 'Chi phí bán biến đổi & Acceptable \\
\hline
\end{tabular}




\begin{tabular}{|c|c|c|}
\hline $\begin{array}{l}\text { costs/Semi-fixed } \\
\text { costs/Mixed costs }\end{array}$ & $\begin{array}{l}\text { Chi phí bán cố định } \\
\text { Chi phí hỗn hợp' }\end{array}$ & \\
\hline $\begin{array}{l}\text { Other cost behaviour } \\
\text { patterns }\end{array}$ & $\begin{array}{l}\text { 'Các mẫu hành vi chi } \\
\text { phí khác' }\end{array}$ & $\begin{array}{l}\text { The meaning is not } \\
\text { clear } \\
\text { Dịch đúng "các cách } \\
\text { ứng xử chi phí khác" }\end{array}$ \\
\hline $\begin{array}{l}\text { Cost behaviour and } \\
\text { cost per unit }\end{array}$ & $\begin{array}{l}\text { 'Hành vi chi phí và } \\
\text { giá mối đơn vị’' }\end{array}$ & $\begin{array}{l}\text { Incorrect } \\
\text { Dịch đúng “ cách } \\
\text { ứng xử của chi phí và } \\
\text { chi phí đơn vị” }\end{array}$ \\
\hline $\begin{array}{l}\text { Assumption about } \\
\text { cost behaviour }\end{array}$ & $\begin{array}{l}\text { 'Giả định về hành vi } \\
\text { chi phí' }\end{array}$ & $\begin{array}{l}\text { The meaning is not } \\
\text { clear }\end{array}$ \\
\hline $\begin{array}{l}\text { Determining the } \\
\text { fixed and variable } \\
\text { elements of semi- } \\
\text { variable costs } \\
\end{array}$ & $\begin{array}{l}\text { 'Xác định các yếu tố } \\
\text { cố định và biến đồi } \\
\text { của chi phí bán biến } \\
\text { đổi' }\end{array}$ & Acceptable \\
\hline Analysing costs & 'Phân tích chi phí' & Acceptable \\
\hline High-low method & $\begin{array}{l}\text { 'Phương pháp cao } \\
\text { thấp' }\end{array}$ & Acceptable \\
\hline Linear equations & $\begin{array}{l}\text { 'Các phương trình } \\
\text { tuyến tính' }\end{array}$ & Acceptable \\
\hline $\begin{array}{l}\text { Example: Deriving a } \\
\text { linear equation }\end{array}$ & $\begin{array}{l}\text { 'Ví dụ: Lập phương } \\
\text { trình tuyến tính’ }\end{array}$ & Acceptable \\
\hline $\begin{array}{l}\text { Linear equation and } \\
\text { graphs }\end{array}$ & $\begin{array}{l}\text { 'Phương trình tuyến } \\
\text { tính và đồ thị' }\end{array}$ & Acceptable \\
\hline $\begin{array}{l}\text { The intercept and the } \\
\text { slope }\end{array}$ & $\begin{array}{l}\text { 'Điểm giao nhau và } \\
\text { độ dốc' }\end{array}$ & $\begin{array}{l}\text { Incorrect } \\
\text { Dịch đúng "hệ số } \\
\text { chặn và độ dốc" }\end{array}$ \\
\hline
\end{tabular}

From the comparison table, it can be seen that in the majority of titles, Google translate gives acceptable results with short and stereotyped titles. However, with long and specialized titles, a translator's intervention is required to ensure accuracy. The cause of the wrong translation may be that automatic translation software tends to translate single words and misinterpret specialized terms. For example, the title "Fixed cost" is translated by google as "fixed price", while the correct translation should be "fixed cost". Or the title "the intercept and the slope" is translated by google as "intersection and slope", but in the field of economics this title should be translated correctly as "intercept and slope".

A term has the characteristic that it represents only a single concept without causing any confusion. In order to evaluate the quality of a term translation, it must ensure three characteristics of the term, which are accuracy, systematic and national and international (Bowker \& Ciro, 2019).

Table 2 is a complete list of management accounting terms in chapter 3 Cost behavior of Management Accounting textbook (BPP, 2019).

\section{TABLE II}

\begin{tabular}{|c|c|c|}
\hline Terms & Google Translate & Human translate \\
\hline Cost behaviour & Hành vi chi phí & Hành vi của chi phí \\
\hline Fixed cost & Chi phí cố định & Chi phí cố định \\
\hline Step cost & Chi phí bước & Chi phí cấp bậc \\
\hline Variable cost & Chi phí biến đổi & Chi phí biến đổi \\
\hline
\end{tabular}

\section{\begin{tabular}{l|l|l} 
Mixed cost & Chi phí hỗn hợp & Chi phí hỗn hợp
\end{tabular}}

Vietnamese versions are translated by google translate, of the five terms, $4 / 5$ are translated close to the human translation. Errors that google translate can come from many causes. Firstly, the successful translation terms are mostly short and simple, the Vietnamese equivalents are usually a single word. While terms are longer or more complex, having multiple equivalents often makes Google translate confusing to display. Secondly, there is currently no standard system for terms in management accounting, which is also the most important factor affecting the quality of automatic translation software. Vietnamese is not a common language in the world, so it is inevitable that automatic translation tools have difficulty converting terms between the two languages. This can be seen in the translation of the word "step cost". Google translate could not process the whole phrase, instead it split the word into two single words "step" and "cost", processed it separately and then put it together in Vietnamese into the word "step cost". Thus, this translation method is not always effective in Vietnamese terms.

\section{B. Students' frequency in using $G T$}

In order to understand students' use GT and their attitudes, feelings and behaviors towards GT, the study selected a sample of 155 undergradute students through shared link of Google forms survey questionnaires. The study was carried out at Faculty of Auditing and Accounting, Hanoi University of Industry. These students are learning module of Management Accounting in 2021 academic year.

The results showed that 100 percent students used GT (see Figure 4). Most of these GT users frequently used GT at least twice a week, whereas some students almost used GT every day or "uncountable". These findings indicated that GT plays a significant role in supporting students' learning.

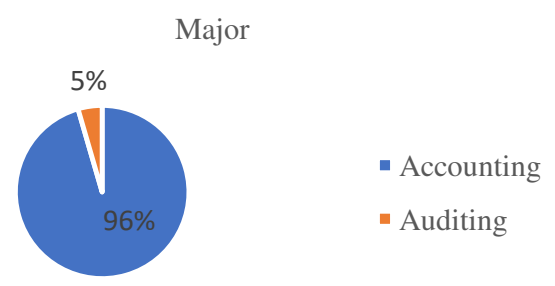

Do you like English

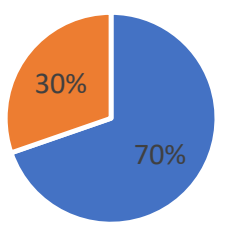

- Yes

- No 


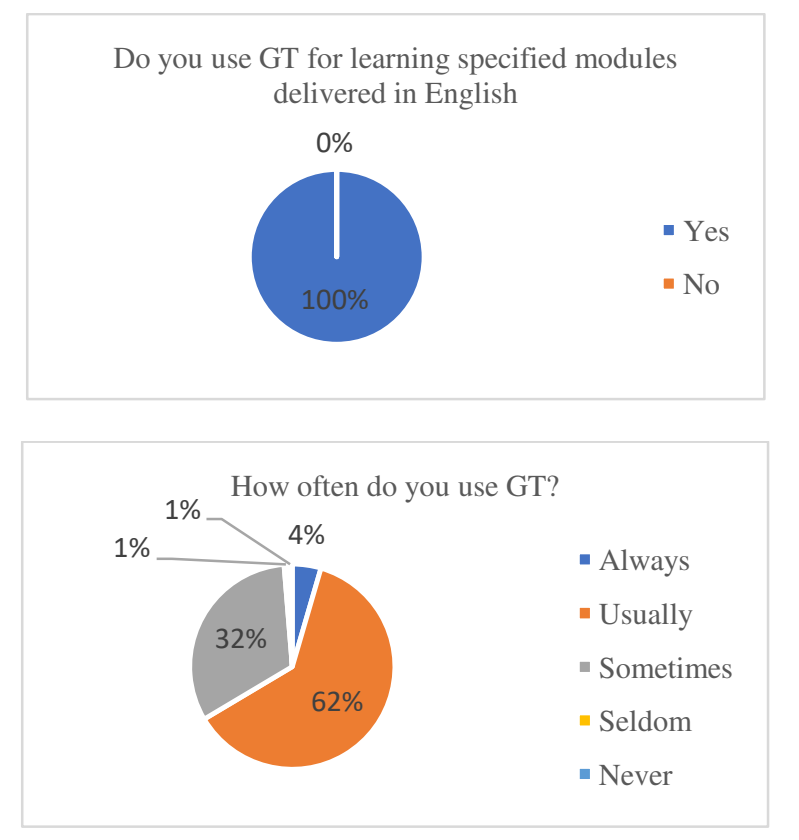

Fig 4. Students' frequency in using GT

When using Google translation to translate assignments or exercises of Management Accounting module, students usually "read sentences and text before using GT" (X = 3.32, S.D = 0.82), "used GT only for meanings of unknown vocabulary words and translated the rest by myself" $(X=3.63$, S.D = 0.79). They used GT to "translate one sentence at a time" $(\mathrm{X}=3.13$, S.D = 0.83), a paragraph $(\mathrm{X}=3.32, \mathrm{~S} . \mathrm{D}=$ 0.92), parts of an essay/article consisting of two paragraphs or more $(X=3.26$, S.D $=1.0)$, a whole essay/article $(X=3.15$, $\mathrm{S} . \mathrm{D}=1.09)$. These results indicated that these were the behaviors of reading sentences and texts before using GT. Students translate one sentence at a time, then look for and replace more suitable words and finally edit the GT output. Almost students knew how to use GT in an effective and appropriate way. They are aware of GT limitations and tried to avoid those errors. They also know how to check and correct the errors. When they were not sure about word meanings translated by GT, they tried to find another suitable word by clicking on those words to see other possible alternatives and chose the most appropriate ones $(\mathrm{X}=3.74$, S.D $=0.92)$; and they asked for other students' help $(X=3.18, S . D=0.94)$.

\section{Students' attitudes towards using GT for learning purposes}

Students were high in favor of GT because GT gives more advantages than disadvantages $(X=3.52, S . D=0.71)$; free and easy to access $(X=4.15$, S.D $=0.79)$; quick to translate texts $(X=3.99, S . D=0.74)$; better quality of texts translated by GT $(X=3.46$, S.D $=0.82)$. From the students' point of view, they agreed that the quality of translated messages by GT was much better than theirs. Thus, students stated that GT could help both students with low and high English ability.

However, some students thought that GT negatively affects their learning habits in different ways. GT made them lazy to think and to use my effort in understanding English (X
$=3.26$, S.D $=0.96)$. They gave the opinion that students with low English competency depend more on GT in learning English rather than those with high level $(X=3.26$, S.D = 0.96). These findings consistent with Maulidiyah (2018), found that students' attempt in reading and writing were reduced, and problems of vocabulary retention appeared when they used GT.

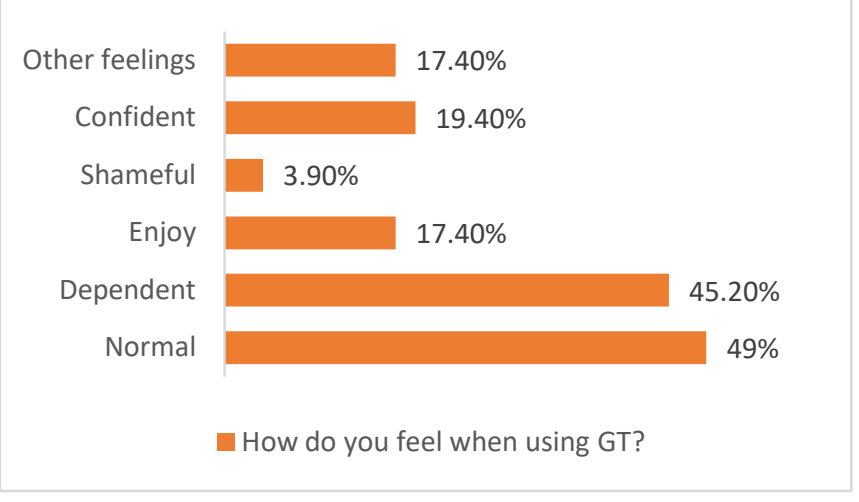

Fig 5. Students' feeling about using GT

When being asked how to feel when using GT, nearly a half of students felt normal (49\%) or dependent (45.2\%). This is in line with the result indicating that students might feel reliant on GT and that GT demotivated their attempt to learn English by themselves. Most of the time they did not try to attempt to read a text in the target language, but had it translated immediately by GT.

Furthermore, in terms of problems of using GT, this study showed that GT could be problematic in some ways. First, it sometimes provides inaccuracy and inappropriateness of word meanings. Second, word order of GT output might be wrong when there are different grammar structure between source and target languages. Dealing with these problems, students suggested that they confirmed word meanings by rechecking them with a dictionary or another translating apps, or even asked for teachers and friends' help. However, students still suggested that GT is more favorable and beneficial.

\section{IMPLICATIONS AND FUTURE DIRECTION}

In conclusions, automatic translation tools, particularly Google translate, have some significant advantages. First, it provides a translation in a very short time, much faster than manual translation. Therefore, it helps to save time significantly, especially when dealing with large volumes of documents. Second, automatic translation software can translate almost any language, even if the source text has a combination of different languages, automatic translation can still handle it. Otherwise, two translators may be required, which can be costly.

On the contrary, automatic translation still has weaknesses that affect translation quality. First, automatic translation lacks consistency in translation versions, which comes from rigid systematic rules in pre-written translation software. Second, automatic translations have low reliability due to the lack of proofreading, so widespread use in highly 
specialized fields is not feasible. The final limitation is insecurity. Information may be lost or leaked or exploited by the provider itself. In addition, this software does not have an archiving feature, so the translations also need to be controlled and managed by the user.

Translation is an inevitable first step and an integral part of the bilingual classroom. Therefore, the aim of the study is to provide some ideas for effective use of Google translate in specialized classes delivered in English. Proper application of instant machine translation tools will improve teaching and learning in English. Research shows that users use Google translate in three aspects: vocabulary, spelling and grammar. Among them, vocabulary becomes the most useful aspect of Google translate, with the word level being the most common, followed by the phrase level, and finally the sentence level. Grammar is the least useful aspect because accuracy is often reduced in some complex cases.

Through evaluating the quality of the translation of Chapter 3 of the Management Accounting textbook translated by Google, compared with the human-translated translation, the study shows that using automatic translation software is relatively effective in case of need for assistance. It is timesaving. Automatic translation tools are increasingly improved thanks to outstanding features of artificial intelligence. User contributions also make using Google translate more and more convenient and necessary in the future. Therefore, within the specialized classroom, the Google Translate automatic translation tool still promotes efficiency and speed, helping students to understand the basic content in the document. Most simple words and phrases are translated relatively accurately and do not require much editing. However, a careful translation process, discussion under the guidance and support of the lecturer is necessary to ensure the quality of the translation.

In some cases, with documents with a high level of specialization, the use of automatic translation software may not be appropriate. For specialized terms, accuracy and consistency in translation when using Google translate is a disadvantage, which greatly affects the quality of the translation. In addition, errors in word deviation and word abuse often occur, making users confused or misinterpret the meaning of the text. Therefore, in most cases, automatic translation is still not a substitute for translators and still requires human intervention and correction.

Results also showed that 100 percent of the students have used Google translate in learning, especially for vocabulary learning and translating. The majority of students agreed that the quality of texts translated by GT is better than by their translation. Besides, they had highly positive attitudes towards google translate, for example, free access, quick and helpful for translating. However, some problems are also reported. GT is unable to translate all the words correctly and sometimes gives inappropriate meanings, requiring students to recheck word meanings from dictionaries or ask for teachers and friends' help. Some students feel too reliant on GT, which reduces their attempt to learn English by themselves. Most students hold beliefs that GT could produce some mistakes in vocabulary choices; hence they might reduce these mistakes by performing these four behaviors, including reading the whole sentences and texts and trying to understand the context before using GT, translating one sentence or a range of words, looking for and replacing more suitable words by checking other sources, and editing the GT output as many as possible. They proposed solutions for improve the situation, such as usage of dictionaries or Grammarly apps.

Research shows that using Google translate tool in teaching-learning specialized subjects in English is feasible and useful as a support tool for lecturers and students. However, this study also has the limitation that it applied google translate in translating text from English to Vietnamese at an initial basic level. The use of GT in a range of classroom activities such as group activities, discussion, writing from English to Vietnamese or vice versa, translating from Vietnamese to English needs to be further studied through other methods such as interview or experimental research to verify. The author proposes to carry out further research to examine the effectiveness of using Google translate in practical classroom activities through in-depth interview methods, questionnaire survey and experimental research in the future.

\section{REFERENCES}

[1] Bowker L., Ciro J. B., 2019. Machine translation and global research: Towards improved machine translation literacy in the scholarly community: Emerald Group Publishing.

[2] Hatim B., Munday J., 2004. Translation: An advanced resource book. Psychology Press.

[3] Jin L., Deifell E., 2013. Foreign language learners' use and perception of online dictionaries: A survey study. Journal of Online Learning and Teaching, 9(4), 515

[4] Kelly N., Zetzsche J. O., 2012. Found in translation: How language shapes our lives and transforms the world. TarcherPerigee.

[5] Kroulek A., 2017. A translation showdown: Man vs machine translation. K-International Language Blog.

[6] Lan P. P., 2019. Evaluating the differences between human translation and machine translation- An implication for teaching and learning translation course for construction materials in the national economics university (NEU) . Educaitional Sciences, 64(12), 50-63. Retrieved from http://stdb.hnue.edu.vn. doi: 10.18173/2354-1067.2019-00131

[7] Larson M. L., 1984. Meaning-based translation: A guide to crosslanguage equivalence (Vol. 366). University press of America Lanham, MD.

[8] Medvedev G., 2016. Google translate in teaching English. Journal of Teaching English for Specific and Academic Purposes, 4(1), 181-193. Newmark P., 1988. A textbook of translation (Vol. 66). Prentice hall New York.

[9] Newmark P., 1988. A textbook of translation (Vol. 66). Prentice hall New York.

[10]Souhila D., 2015. Developing EFL writing skill through the use of the process approach. University of Biskra.

[11]Starkey L. B., 2004. How to write great essays. LearningExpress.

[12]Van Rensburg A., Snyman C., Lotz S., 2012. Applying Google Translate in a higher education environment: Translation products assessed. Southern African linguistics and applied language studies, 30(4), 511-524.

[13]Zafitri L., Harida E. S., 2017. The effectiveness of using google translateon students' translation at mathematic faculty of Universitas Negeri Padang. Proceedings of ISELT FBS Universitas Negeri Padang, 5, 80-85.

[14]Sukkwan, A. 2014. Students' Attitudes and Behaviors towards the Use of Google Translate: A Thesis. Prince of Songkla University, Thailand (retrieved on November 2, 2017). 